\title{
Identification of genes potentially involved in bone metastasis by genome-wide gene expression profile analysis of non-small cell lung cancer in mice
}

\author{
LE TAN DAT $^{1,2}$, TAISUKE MATSUO ${ }^{1}$, TETSURO YOSHIMARU ${ }^{1}$, SOJI KAKIUCHI ${ }^{2}$, \\ HISATSUGU GOTO ${ }^{2}$, MASAKI HANIBUCHI ${ }^{2}$, TAKUYA KURAMOTO ${ }^{1}$, \\ YASUHIKO NISHIOKA ${ }^{2}$, SABURO SONE $^{2}$ and TOYOMASA KATAGIRI ${ }^{1}$ \\ ${ }^{1}$ Division of Genome Medicine, Institute for Genome Research, The University of Tokushima; \\ ${ }^{2}$ Department of Respiratory Medicine and Rheumatology, Institute of Health Biosciences, \\ The University of Tokushima Graduate School, Tokushima 770-8503, Japan
}

Received October 26, 2011; Accepted December 22, 2011

DOI: 10.3892/ijo.2012.1348

\begin{abstract}
Lung cancer is commonly associated with multiorgan metastasis, and the bone is a frequent metastatic site for lung cancer. However, the molecular mechanism of organspecific metastasis remains poorly understood. To elucidate this issue, we analyzed in this study genome-wide gene expression profiles of 15 metastatic lesions from three organs (bone, lung and liver) in a mouse model with multi-organ metastasis properties of human non-small cell lung cancer cells (ACC-LC319/ bone2), using a combination of laser-microbeam microdissection and DNA microarrays. We identified 299 genes that could potentially be involved in the organ-selective nature of lung cancer metastasis. Among them, 77 were bone-specifically expressed elements, including genes involved in cell adhesion, cytoskeleton/cell motility, extracellular matrix remodeling and cell-cell signaling as well as genes already known to be involved in the bone metastasis of breast cancers. Quantitative RT-PCR confirmed the specific upregulation of eight genes in bone metastasis tumors, suggesting that these genes may be involved in bone metastasis. Our findings should be helpful for a better understanding of the molecular aspects of the metastatic process in different organs, and could lead to molecular target-based anticancer drugs and prevention of metastasis, especially bone metastasis.
\end{abstract}

\section{Introduction}

Lung cancer is the leading cause of mortality worldwide and its incidence is rising in many countries (1). The high mortality

Correspondence to: Dr Toyomasa Katagiri, Division of Genome Medicine, Institute for Genome Research, The University of Tokushima, 3-18-15, Kuramoto-cho, Tokushima 770-8503, Japan E-mail: tkatagi@genome.tokushima-u.ac.jp

Key words: lung cancer, expression profiling, bone metastasis of this disease is predominantly due to the difficulty of early diagnosis and the highly metastatic potential of lung cancer. In many cases, metastases to multiple organs have already developed by the time of diagnosis (2-4). In particular, $\sim 30-40 \%$ of patients with advanced lung cancer will develop bone metastases in the course of their disease, resulting in a significant negative impact on both morbidity and survival (3-5). Currently no curative therapy exists for bone metastasis, and clinical management is generally palliative $(3,6,7)$. Hence, the prevention and treatment of bone metastases are clinically vital.

Most treatments for lung cancer bone metastases are proposed based on targeting the osteoclast-activating pathway, which is the key deregulation in bone metastasis in many types of cancers (3,6-10). However, the cancer cells metastasizing to the bone may express certain features that mediate and favor their colonization in the bone, as well as disrupt the normal balance of bone formation and bone resorption $(6,7,9)$. During such tumor progression, cancer cells are thought to acquire several genetic alterations. We believe that identifying such molecular changes in the cancer cells themselves can probably help to solve, at least in part, bone metastases in lung cancer. In order to understand the molecular mechanism of metastasis, especially bone metastasis, and to establish a moleculartargeted therapy, the development of a clinically relevant animal model is essential. A complex approach of animal models and transcriptomic analyses can provide a considerable amount of information for characterizing the nature of individual cancers; the promise of such information lies in its potential for improving clinical strategies for treatment of cancer through development of novel drugs $(5,11,12)$. With that goal in mind, we performed gene expression profiling in a multiple-organ metastasis mouse model of human small cell lung cancer cells (SCLC), and identified a dozen candidate genes that may affect or determine organ specificity of the metastatic cells, as well as genes involved metastatic processes in different microenvironments (11).

To investigate the molecular bases of organ-specific metastasis, especially the bone, we previously established a multiple-organ metastasis mouse model of human non-small 
cell lung cancer cells (NSCLC; ACC-LC319/bone2), and performed transcriptomic analysis of in vivo metastatic tissues to propose new profiles of lung cancer metastases to multiple organs, including bone metastases. Here, we showed organspecific gene expression profiles of metastases in the bone, lung and liver, and selectively validated the findings of eight genes in the 'bone profile'. The data from these experiments not only should provide important information about the organ-tropism nature of NSCLC-metastasis, but also be valuable for identifying candidate genes whose products might serve as molecular targets for treatment of NSCLC metastasis, especially bone metastasis.

\section{Materials and methods}

Cell lines. A human lung adenocarcinoma cell line ACC-LC319/bone2 with a high bone metastasis ability was established as described previously (13). We confirmed no Mycoplasma contamination in cultures of the cell line used in vitro and in vivo using PCR Mycoplasma Detection set (Takara, Shiga, Japan). No abnormalities were observed on the cellular morphology of this cell line either at high or low densities of cultures by microscopy. Cells were cultured in RPMI-1640 medium (Invitrogen, Carlsbad, CA), supplemented with $10 \%$ fetal bovine serum (Nichirei Biosciences, Tokyo, Japan), antibiotic-antimycotic mixture (Invitrogen), and incubated at $37^{\circ} \mathrm{C}$ in a humidified atmosphere containing $5 \%$ of $\mathrm{CO}_{2}$.

In vivo mouse model. Seven-week-old male SCID mice (C.B-17) Icr-scid/scidJcl, CLEA Company, Japan) were depleted of NK-cells and intravenously inoculated with ACC-LC319/bone2 cells as described previously (13). The mice were sacrificed on the 34th day after tumor cell inoculation, and the lungs, livers and hind limp bones containing macroscopic lesions were embedded in Tissue Tek OCT medium (Sakura, Tokyo, Japan), and snap frozen in liquid nitrogen and stored at $-80^{\circ} \mathrm{C}$ until use. All the experiments in mice were performed under the Guidelines for Animal Welfare in The University of Tokushima, Tokushima.

Laser microbeam microdissection. The frozen tissues were cut into 8-10 $\mu \mathrm{m}$ sections and applied to PEN-membrane slide (Leica, Herborn, Germany), and then stained with hematoxylin and eosin (H\&E) for histological examination. The stained tissues were observed microscopically; 15 metastatic lesions ( 5 bones, 5 lungs and 5 livers) were selectively obtained for laser-microbeam microdissection using PALM Microbeam system (Carl Zeiss, Jena, Germany) according to the manufacturer's protocols. To avoid cross-hybridization of normal mouse mRNA on DNA microarray as described below, we microdissected normal mouse cells in the surrounding regions far from the metastatic lesions of each of the three organs (bone, lung and liver).

RNA extraction, RNA amplification and DNA microarray. Total RNA from each microdissected tissue and the in vitro cell line ACC-LC319/bone2 were extracted using RNeasy mini kit (Qiagen, Valencia, CA, USA) according to the manufacturer's protocol. The purity and integrity of RNA were assessed by NanoDrop system (Thermo Scientific, Wilmington, Delaware,
USA) and Agilent RNA 6000 Nano Bioanalyzer (Agilent Technologies), respectively. RNA amplification and labeling of complementary RNA (cRNA) with Cy3 dye were performed using Agilent Low-Input QuickAmp Labeling kit according to the manufacturer's protocol. The Whole Human Genome $4 \times 44 \mathrm{~K}$ Oligomicroarray kit containing 41,193 probes (60-mer oligo DNA, including control probes) and Gene Expression Hybridization kit were used for the hybridization of labeled RNA. Scanning analysis was performed using the Agilent Microarray scanner and the acquired array images were processed using the Agilent Feature Extractions version 9.5. All the experimental protocols employed followed the manufacturer's protocol (Agilent Technologies).

Microarray data analysis. Microarray data generated by the feature extraction software were loaded in GeneSpring software, version 11.5 (Agilent Technologies). First, we normalized the microarray data across all chips and all genes using quantile normalization, and baseline transformed the signal values to the median in all samples. Then we performed quality control and filtering of the data by flags and by expression level. Entities with flag 'Detected' in at least one out of 18 samples and had values within the 20 and 100th percentiles in at least one out of 18 samples were retained for further analysis.

To identify genes that were differentially expressed among the three types of metastatic tissue, we grouped all five metastases in each of the three organs (bone, lung, liver), and then compared the fold change of expression in one group with the other pool of ten metastases in the other two organs, e.g. five bone metastases would be grouped as 'bone metastases', and compared with the group 'lung and liver metastases' that included five lung metastases and five liver metastases, and so on. We applied random permutation test 10,000 times for each comparison and adjusted for multiple comparison using the Benjamini-Hochberg false discovery rate (FDR). Gene expression level was considered significantly different when FDR was $<0.05$ (corrected P-value $<0.05$ ), and the fold change was at least 2.0 between groups. The output gene lists were further interpreted based on gene ontology analysis.

To rule out the cross-hybridization of normal mouse mRNA to human, we microdissected normal mouse cells from each organ, lung, liver and bone, and hybridized them on human DNA microarrays (Agilent) by the same method as described above. The contamination of mouse genes, if any, most likely had signal intensities above a certain cut-off value. We arbitrarily selected the 95th percentile value of the signal intensities value in metastasis in each organ as the cut-off value, and excluded those genes with signal intensity values higher than this cut-off value in the corresponding normal mouse tissues in each of these three organs.

For hierarchical cluster analysis, the normalized signal intensities of upregulated genes in each organ were subjected to Cluster 3.0 (14), and clustered based on the centroid linkage. The output data were organized using TreeView 1.60 (15). Data from this microarray experiment has been submitted to the NCBI Gene Expression Omnibus (GEO) archive as series GSE29391.

Reverse transcription and real-time RT-PCR. Total RNAs extracted from each of the microdissected tumor samples were 
Table I. Primers used in real-time RT-PCR.

\begin{tabular}{|c|c|c|}
\hline Gene & Fordward primer $\left(5^{\prime}-3^{\prime}\right)$ & Reverse primer $\left(5^{\prime}-3^{\prime}\right)$ \\
\hline$G A P D H$ & GATCATCAGCAATGCCTCCTG & GAGTCCTTCCACGATACCAAAG \\
\hline TTYH1 & TGTGCTCCCATTTCTGTCCTT & TGCCAGCCCTACTCCCTAGTC \\
\hline LEFTY1 & TTGGGGACTATGGAGCTCAG & TCAAGTCCCTCGATGGCTAC \\
\hline GUCY1B3 & AACAGTGTTTGGCCATGTG & GCTGCCTGTGGTTAATGAG \\
\hline TM4SF4 & GCTTCCTGGCTAACATCCTGTTA & ACACCAGCGCAGGGAAGAT \\
\hline FOLRI & GTCGACCCTGGAGGAAGAAT & GCCATCTCTCCACAGTGGTT \\
\hline FGFR3 & TCAGGGTGGTCTCTTCTTGG & CGTCGCTGGGTTAACAAAAT \\
\hline METLL7A & GAGCCCCTAAACATCAAGCA & TTCCAACAGGGGTGGAATTA \\
\hline$C R Y M$ & GAGTGAAACCAGCCCACTGT & TTGGCTGCAACTGTGTCTTC \\
\hline
\end{tabular}
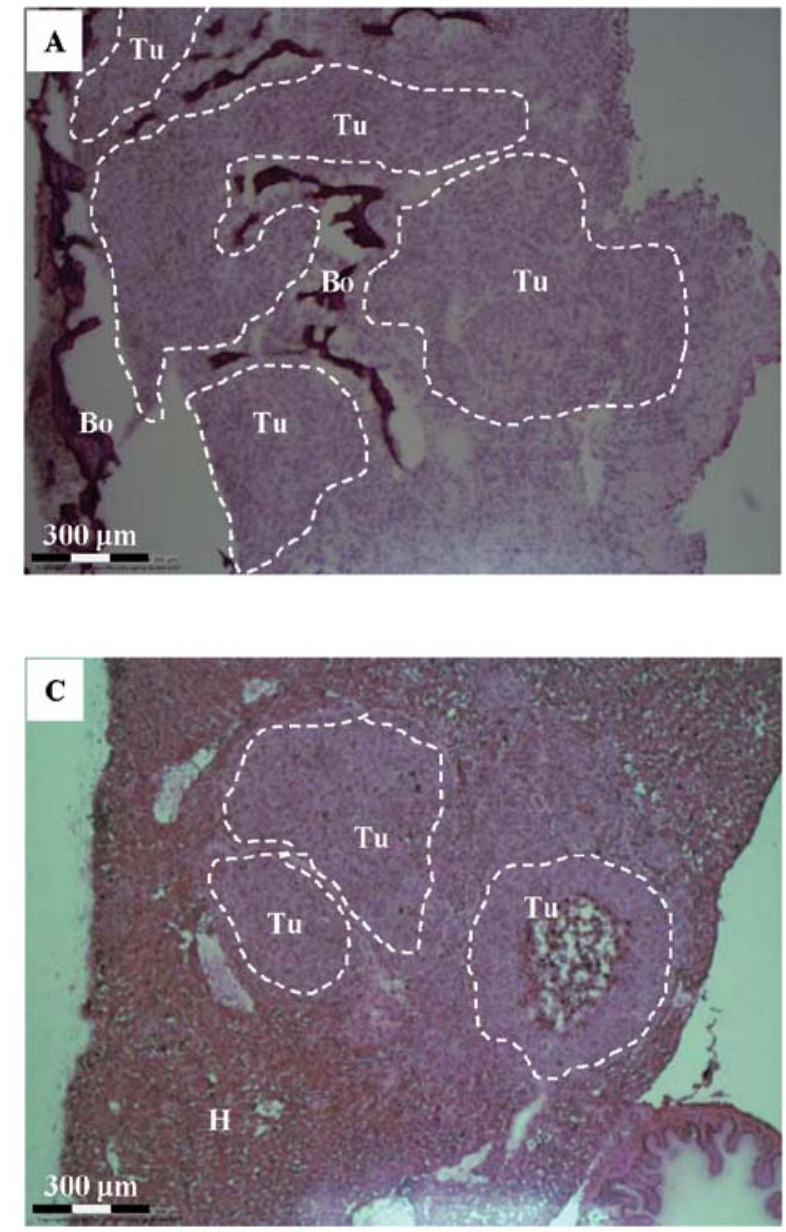

Figure 1. Histopathology of metastatic lesions in the bone (A), lung (B) and liver (C) (H\&E staining). Tu, tumor tissue (dotted area, in some tumors there were necrotic and hemorrhagic regions); $\mathrm{H}$, hepatocyte (normal tissue in liver); $\mathrm{P}$, pneumocyte (normal tissue in lung); Bo, bone (dark area); Scale bars, $300 \mu \mathrm{m}$.

reverse-transcribed by SuperScript II reverse-transcriptase (Invitrogen), asccording to the manufacturers protocol. We prepared appropriate dilutions of each single-stranded cDNA for subsequent PCR by monitoring the glyceraldehyde-3-phosphate dehydrogenase (GAPDH) as a quantitative internal control. Quantitative PCR were performed using SYBR Premix

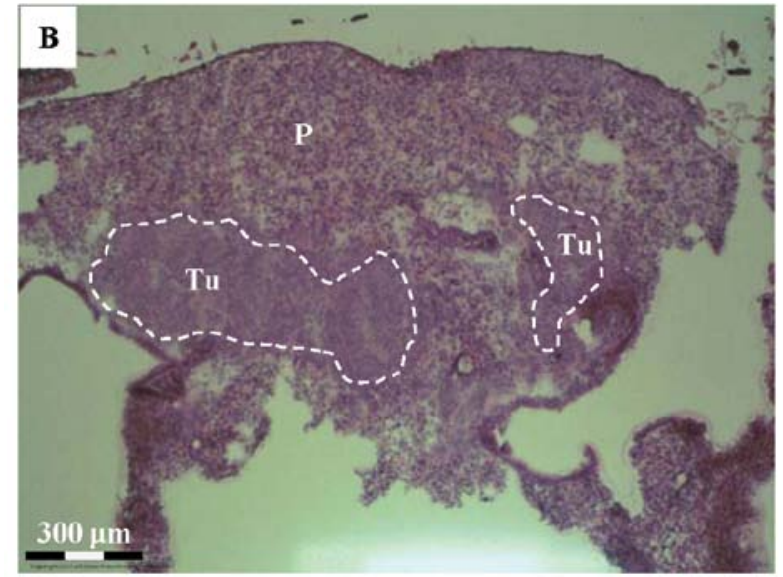

Ex Taq (Takara) on Applied Biosciences Fast real-time 7500 system (Applied Biosciences). All the primers used in PCRs are listed in Table I.

Statistical analysis. The difference in gene expression level evaluated by quantitative PCR was examined by Student's t-test (using Microsoft Excel 2007), with p-value $<0.05$ as significant threshold.

\section{Results}

Evaluation of metastatic lesions in multi-organ metastasis model. To obtain precise gene-expression profiles of 15 selected metastatic lesions (five in each organ: lung, liver, and bone) in a mouse model, we purified cancer cells from each organ by lasermicrobeam microdissection (see Materials and methods). The representative histopathological features of each of metastatic lesions in bone, lung and liver are shown in Fig. 1. Consistent with previous results (13), all mice developed metastases in bones as evaluation by overt clinical signs, sick mice showed limping due to fractures of hind limps, together with other signs such as weight loss, ruffling fur, dyspnea, big belly, but we collected osteolytic lesions in this microarray analysis because osteoblastic lesions were observed to a much lesser extent $(\sim 30 \%)$ (Fig. 1A). We also observed metastatic lesions in lungs and livers of all mice (Fig. $1 \mathrm{~B}$ and $\mathrm{C}$ ). 
Table II. Bone metastasis gene expression profile of upregulated genes with FC $>2.0$, and P-value $<0.05$.

\begin{tabular}{lc}
\hline Gene symbol & Accession number \\
\hline Cell adhesion & \\
SNED1 & NM_001080437 \\
TTYH1 & NM_020659 \\
GPR98 & AL136541 \\
SPON2 & NM_012445
\end{tabular}

Cytoskeleton/cell motility

$\begin{array}{ll}\text { MYL1 } & \text { NM_079420 } \\ \text { TNNI2 } & \text { NM_003282 } \\ \text { MYO1A } & \text { NM_005379 } \\ \text { TTLL6 } & \text { NM_173623 }\end{array}$

Sushi, nidogen and EGF-like domains 1

Tweety homolog 1 (Drosophila)

$\mathrm{G}$ protein-coupled receptor 98

Spondin 2, extracellular matrix protein

Myosin, light chain 1, alkali; skeletal, fast

Troponin I type 2 (skeletal, fast)

Myosin IA

Tubulin tyrosine ligase-like family, member 6

Collagen, type VIII, $\alpha 1$

Collagen, type VI, $\alpha 3$

NM 001850

COL6A3

NM_004369
P-value

Fold change

Cell-cell signaling (cytokine/chemokine)

$\begin{array}{lc}\text { LEFTY1 } & \text { NM_020997 } \\ \text { CDNF } & \text { NM_001029954 } \\ \text { CHIA } & \text { NM_021797 }\end{array}$

Left-right determination factor 1

Cerebral dopamine neurotrophic factor

Chitinase, acidic

$\begin{array}{rr}<0.001 & 2.494 \\ 0.016 & 2.374 \\ 0.047 & 2.110 \\ 0.020 & 2.029\end{array}$

0.020

5.571

$0.036 \quad 5.211$

$0.025 \quad 2.677$

$<0.001 \quad 2.570$

Signal transduction

$\begin{array}{lc}\text { PPPIR1B } & \text { NM_032192 } \\ \text { GUCY1B3 } & \text { NM_000857 } \\ \text { DOK7 } & \text { NM_173660 } \\ \text { TM4SF4 } & \text { NM_004617 } \\ \text { PTPRD } & \text { NM_002839 } \\ \text { ARHGAP29 } & \text { BC022483 } \\ \text { FOLR1 } & \text { NM_016725 } \\ \text { CLEC11A } & \text { NM_002975 } \\ \text { FGFR3 } & \text { NM_000142 }\end{array}$

Protein phosphatase 1 , regulatory (inhibitor) subunit $1 \mathrm{~B}$

0.020

2.933

0.016

2.246

Guanylate cyclase 1 , soluble, $\beta 3$

Docking protein 7

Transmembrane $4 \mathrm{~L}$ six family member 4

Protein tyrosine phosphatase, receptor type, D

0.020

2.836

$0.020 \quad 2.654$

$0.046 \quad 2.302$

Rho GTPase activating protein 29

Folate receptor 1 (adult)

C-type lectin domain family 11 , member A

Fibroblast growth factor receptor 3, variant 1

0.016

3.376

0.020

2.613

0.046

2.463

0.032

2.429

0.011

2.222

0.016

2.211

0.020

2.178

0.010

2.101

0.013

2.071

Immune response

$\begin{array}{lc}\text { POU2AF1 } & \text { NM_006235 } \\ \text { PLA2G1B } & \text { NM_000928 } \\ \text { RNF 125 } & \text { AK027134 }\end{array}$

POU class 2 associating factor 1

$0.010 \quad 4.962$

Phospholipase A2, group IB (pancreas)

Ring finger protein 125

2.298

$\begin{array}{ll}0.016 & 2.298 \\ 0.016 & 2.076\end{array}$

Metabolism/catalytic activity

$\begin{array}{lc}\text { PNMT } & \text { NM_002686 } \\ \text { C3orf57 } & \text { NM_001040100 } \\ \text { ECHDC3 } & \text { NM_024693 } \\ \text { CTSO } & \text { NM_001334 } \\ \text { NUDT7 } & \text { NM_001105663 } \\ \text { METTL7A } & \text { NM_014033 } \\ \text { ADPRHL1 } & \text { NM_138430 } \\ \text { PACSIN1 } & \text { NM_020804 } \\ \text { GPIHBP1 } & \text { NM_178172 } \\ & \\ \text { FMO5 } & \text { NM_001461 } \\ \text { PACSIN1 } & \text { NM_020804 } \\ \text { CRYM } & \text { NM_001888 } \\ \text { STK31 } & \text { NM_032944 } \\ M D H 1 B & \text { BC033509 } \\ \text { SPTLC3 } & \text { NM_018327 }\end{array}$

Phenylethanolamine N-methyltransferase

$0.020 \quad 3.681$

Chromosome 3 open reading frame 57

$0.010 \quad 3.361$

$0.010 \quad 3.086$

Enoyl Coenzyme A hydratase domain containing 3

0.032

2.766

Nudix (nucleoside diphosphate linked moiety X)-type

0.024

2.617

Methyltransferase like 7A

$0.015 \quad 2.420$

ADP-ribosylhydrolase like 1

$<0.001$

2.370

Protein kinase $\mathrm{C}$ and casein kinase substrate in neurons 1

0.015

2.250

Glycosylphosphatidylinositol anchored high density

0.020

2.210

lipoprotein binding protein 1

Flavin containing monooxygenase 5

0.038

2.178

Protein kinase $\mathrm{C}$ and casein kinase substrate in neurons 1

0.016

2.160

Crystallin, mu

0.040

2.131

Serine/threonine kinase 31

0.032

2.066

Malate dehydrogenase 1B, NAD (soluble)

0.032

2.054

Serine palmitoyltransferase, long chain base subunit 3

$0.016 \quad 2.010$ 
Table II. Continued.

\begin{tabular}{|c|c|c|c|c|}
\hline Gene symbol & Accession number & Gene name & P-value & Fold change \\
\hline \multicolumn{5}{|c|}{ Cell cycle, apoptosis } \\
\hline$D A P L 1$ & NM_001017920 & Death associated protein-like 1 & 0.010 & 9.621 \\
\hline PLK1S1 & ВC039296 & Polo-like kinase 1 substrate 1 & 0.021 & 2.216 \\
\hline \multicolumn{5}{|l|}{ Transcription } \\
\hline N/A & AF023203 & Homeobox protein Og12 (OGL12) & 0.020 & 8.619 \\
\hline \multicolumn{5}{|c|}{ Transporter activity } \\
\hline CACNG7 & NM_031896.4 & Calcium channel, voltage-dependent, gamma subunit 7 & 0.010 & 5.516 \\
\hline$A T P 2 A 1$ & NM_173201 & ATPase, $\mathrm{Ca}^{2+}$ transporting, cardiac muscle, fast twitch 1 & 0.013 & 5.210 \\
\hline CCT6B & NM_006584 & Chaperonin containing TCP1, subunit 6B (§2) & 0.016 & 3.507 \\
\hline SLC16A14 & NM_152527 & $\begin{array}{l}\text { Solute carrier family } 16, \text { member } 14 \text { (monocarboxylic } \\
\text { acid transporter } 14 \text { ) }\end{array}$ & 0.024 & 2.952 \\
\hline SLC5A9 & NM_001011547 & $\begin{array}{l}\text { Solute carrier family } 5 \text { (sodium/glucose cotransporter), } \\
\text { member } 9\end{array}$ & 0.032 & 2.377 \\
\hline$S L C 23 A 1$ & NM_152685 & $\begin{array}{l}\text { Solute carrier family } 23 \text { (nucleobase transporters), } \\
\text { member } 1\end{array}$ & 0.032 & 2.290 \\
\hline SLC16A14 & NM_152527 & $\begin{array}{l}\text { Solute carrier family } 16, \text { member } 14 \text { (monocarboxylic } \\
\text { acid transporter } 14 \text { ) }\end{array}$ & 0.017 & 2.050 \\
\hline$A B C D 3$ & NM_002858 & ATP-binding cassette, sub-family D (ALD), member 3 & 0.016 & 2.034 \\
\hline GLTPD2 & NM_001014985 & Glycolipid transfer protein domain containing 2 & 0.015 & 2.027 \\
\hline \multicolumn{5}{|c|}{ Calcium ion binding } \\
\hline EFHC2 & NM_025184 & EF-hand domain (C-terminal) containing 2 & 0.015 & 4.518 \\
\hline$E F H B$ & NM_144715 & EF-hand domain family, member B & 0.040 & 2.392 \\
\hline$A N X A 13$ & NM_001003954 & Annexin A13 & 0.029 & 2.108 \\
\hline \multicolumn{5}{|l|}{ The others } \\
\hline$I T M 2 A$ & NM_004867 & Integral membrane protein $2 \mathrm{~A}$ & 0.011 & 4.216 \\
\hline$A P C D D 1 L$ & NM_153360 & Adenomatosis polyposis coli down-regulated 1-like & 0.047 & 4.034 \\
\hline RSPH1 & NM_080860 & Radial spoke head 1 homolog (Chlamydomonas) & 0.010 & 3.300 \\
\hline$N E B$ & NM_004543 & Nebulin & 0.015 & 2.603 \\
\hline$D E N N D 1 B$ & AL831839 & DENN/MADD domain containing 1B & 0.032 & 2.011 \\
\hline \multicolumn{5}{|l|}{ Unknown } \\
\hline C17orf108 & NM_001076680 & Chromosome 17 open reading frame 108 & 0.010 & 4.160 \\
\hline C11orf93 & NM_001136105 & Chromosome 11 open reading frame 93 & 0.010 & 3.023 \\
\hline$U N Q 1944$ & AY358202 & RVLA1944 & 0.044 & 2.704 \\
\hline DENND2C & CR749576 & DENN/MADD domain containing 2C & 0.025 & 2.700 \\
\hline FAM167A & NM_053279 & Family with sequence similarity 167, member A & 0.037 & 2.666 \\
\hline$P R Y 2$ & NM_001002758 & PTPN13-like, Y-linked 2 & 0.030 & 2.598 \\
\hline C11orf92 & NM_207429 & Chromosome 11 open reading frame 92 & 0.015 & 2.554 \\
\hline $\mathrm{N} / \mathrm{A}$ & AL833005 & & 0.016 & 2.465 \\
\hline REEP2 & NM_016606 & Receptor accessory protein 2 & 0.010 & 2.319 \\
\hline C17orf108 & ВС042947 & Chromosome 17 open reading frame 108 & 0.034 & 2.300 \\
\hline $\mathrm{N} / \mathrm{A}$ & AK023574 & & 0.040 & 2.253 \\
\hline C16orf73 & NM_152764 & Chromosome 16 open reading frame 73 & 0.017 & 2.214 \\
\hline $\mathrm{N} / \mathrm{A}$ & AJ412029 & & 0.016 & 2.161 \\
\hline N/A & AL834280 & & 0.047 & 2.141 \\
\hline $\mathrm{N} / \mathrm{A}$ & AK055981 & & 0.010 & 2.121 \\
\hline$R P L 27 A$ & NM_000990 & Ribosomal protein L27a & 0.047 & 2.061 \\
\hline $\mathrm{N} / \mathrm{A}$ & AX748211 & & 0.020 & 2.000 \\
\hline
\end{tabular}

P-value, Benjamini-Hochberg false discovery rate of random permutation test; Fold change, ratio of gene expression levels between groups. Gene symbol, accession number, gene name: exported from GeneSpring (from the NCBI databases). FC, fold change; N/A, not available. In each gene ontology functional term, genes were ranked according to fold change (highest to lowest). 
Table III. Lung metastasis gene expression profile of upregulated genes with $\mathrm{FC}>2.0$, and $\mathrm{P}$-value $<0.05$.

\begin{tabular}{|c|c|c|c|c|}
\hline Gene symbol & Accession number & Gene name & P-value & Fold change \\
\hline \multicolumn{5}{|l|}{ Cell adhesion } \\
\hline CLDN18 & NM_016369 & Claudin 18 & 0.003 & 20.878 \\
\hline FLRT3 & NM_198391 & Fibronectin leucine rich transmembrane protein 3 & 0.003 & 6.880 \\
\hline$I G F B P 7$ & NM_001553 & Insulin-like growth factor binding protein 7 & 0.005 & 5.166 \\
\hline$A L C A M$ & NM_001627 & Activated leukocyte cell adhesion molecule & 0.003 & 3.882 \\
\hline$L R R N 2$ & NM_201630 & Leucine rich repeat neuronal 2 & 0.003 & 3.790 \\
\hline PTPRF & NM_002840 & Protein tyrosine phosphatase, receptor type, F & 0.010 & 2.885 \\
\hline$S R P X$ & NM_006307 & Sushi-repeat-containing protein, $X$-linked & 0.031 & 2.510 \\
\hline$P V R L 3$ & $\mathrm{BC} 017572$ & Poliovirus receptor-related 3 & 0.003 & 2.509 \\
\hline$P V R L 3$ & NM_015480 & Poliovirus receptor-related 3 & 0.003 & 2.477 \\
\hline$C G N$ & NM_020770 & Cingulin & 0.019 & 2.472 \\
\hline PVRL3 & BC017572 & Poliovirus receptor-related 3 & 0.009 & 2.462 \\
\hline F5 & NM_000130 & Coagulation factor V (proaccelerin, labile factor) & 0.042 & 2.418 \\
\hline$D D R 2$ & NM_001014796 & Discoidin domain receptor tyrosine kinase 2 & 0.048 & 2.353 \\
\hline$N R P 2$ & NM_018534 & Neuropilin 2 (variant 4 ) & 0.003 & 2.348 \\
\hline$I T G B 2$ & NM_000211 & $\begin{array}{l}\text { Integrin, } \beta 2 \text { (complement component } 3 \text { receptor } 3 \text { and } \\
4 \text { subunit) }\end{array}$ & 0.023 & 2.338 \\
\hline$N R P 2$ & NM_201266 & Neuropilin 2 (variant 1 ) & 0.030 & 2.078 \\
\hline STAB1 & NM_015136 & Stabilin 1 & 0.003 & 2.027 \\
\hline \multicolumn{5}{|c|}{ Cytoskeleton/cell motility } \\
\hline SHROOM3 & NM_020859 & Shroom family member 3 & 0.008 & 8.364 \\
\hline NTN1 & NM_004822 & Netrin 1 & 0.014 & 3.064 \\
\hline KRT80 & NM_182507 & Keratin 80 & 0.014 & 2.544 \\
\hline \multicolumn{5}{|c|}{ Extracellular matrix remodeling } \\
\hline SFTPC & NM_003018 & Surfactant protein $\mathrm{C}$ & 0.003 & 191.604 \\
\hline$S F T P D$ & NM_003019 & Surfactant protein $\mathrm{D}$ & 0.003 & 94.641 \\
\hline GPC3 & NM_004484 & Glypican 3 & 0.037 & 6.034 \\
\hline CHI3L1 & NM_001276 & Chitinase 3-like 1 (cartilage glycoprotein-39) & 0.014 & 5.513 \\
\hline COLAA3 & NM_000091 & Collagen, type IV, $\alpha 3$ (Goodpasture antigen) & 0.047 & 4.716 \\
\hline$T G F B I$ & NM_000358 & Transforming growth factor, $\beta$-induced, $68 \mathrm{kDa}$ & 0.007 & 3.301 \\
\hline COLIA1 & $\mathrm{Z7} 4615$ & Collagen, type I, $\alpha 1$ & 0.007 & 2.657 \\
\hline BMP5 & NM_021073 & Bone morphogenetic protein 5 & 0.034 & 2.443 \\
\hline CPM & NM_001874 & Carboxypeptidase M & 0.023 & 2.233 \\
\hline MATN2 & NM_030583 & Matrilin 2 & 0.014 & 2.190 \\
\hline$V C A N$ & NM_004385 & Versican & 0.038 & 2.156 \\
\hline \multicolumn{5}{|c|}{ Cell-cell signaling (cytokine/chemokine) } \\
\hline$I G F 2$ & NM_000612 & Insulin-like growth factor 2 (somatomedin A) & 0.003 & 6.449 \\
\hline PRICKLE1 & NM_153026 & Prickle homolog 1 (Drosophila) & 0.003 & 5.549 \\
\hline TCN1 & NM_001062 & $\begin{array}{l}\text { Transcobalamin I (vitamin B12 binding protein, R binder } \\
\text { family) }\end{array}$ & 0.016 & 4.445 \\
\hline CAMP & NM_004345 & Cathelicidin antimicrobial peptide & 0.010 & 4.118 \\
\hline PHLDB2 & NM_145753 & Pleckstrin homology-like domain, family B, member 2 & 0.014 & 4.056 \\
\hline NTN4 & NM_021229 & Netrin 4 & 0.003 & 3.243 \\
\hline FSTL1 & NM_007085 & Follistatin-like 1 & 0.019 & 2.893 \\
\hline PRRG3 & NM_024082 & $\begin{array}{l}\text { Proline rich Gla (G-carboxyglutamic acid) } 3 \\
\text { (transmembrane) }\end{array}$ & 0.049 & 2.838 \\
\hline NTN4 & NM_021229 & Netrin 4 & 0.003 & 3.243 \\
\hline FSTL1 & NM_007085 & Follistatin-like 1 & 0.019 & 2.893 \\
\hline PRRG3 & NM_024082 & $\begin{array}{l}\text { Proline rich Gla (G-carboxyglutamic acid) } 3 \\
\text { (transmembrane) }\end{array}$ & 0.049 & 2.838 \\
\hline PRRG3 & NM_024082 & $\begin{array}{l}\text { Proline rich Gla (G-carboxyglutamic acid) } 3 \\
\text { (transmembrane) }\end{array}$ & 0.049 & 2.838 \\
\hline$N T N G 1$ & NM_014917 & Netrin G1 & 0.008 & 2.815 \\
\hline RSPO3 & NM_032784 & R-spondin 3 homolog (Xenopus laevis) & 0.023 & 2.348 \\
\hline
\end{tabular}


Table III. Continued.

\begin{tabular}{|c|c|c|c|c|}
\hline Gene symbol & Accession number & Gene name & P-value & Fold change \\
\hline$I N H B B$ & NM_002193 & Inhibin, $\beta \mathrm{B}$ & 0.022 & 2.181 \\
\hline \multicolumn{5}{|c|}{ Signal transduction } \\
\hline$D K K 1$ & NM_012242 & Dickkopf homolog 1 (Xenopus laevis) & 0.003 & 11.313 \\
\hline RICH2 & NM_014859 & Rho-type GTPase-activating protein $\mathrm{RICH} 2$ & 0.003 & 11.012 \\
\hline$I L 7 R$ & NM_002185 & Interleukin 7 receptor & 0.009 & 7.874 \\
\hline PDGFRA & NM_006206 & Platelet-derived growth factor receptor, $\alpha$ polypeptide & 0.003 & 5.941 \\
\hline$C D C 42 E P 3$ & AK055915 & CDC42 effector protein (Rho GTPase binding) 3 & 0.003 & 5.133 \\
\hline$C D C 42 E P 3$ & NM_006449 & CDC42 effector protein (Rho GTPase binding) 3 & 0.003 & 4.854 \\
\hline GRIA3 & NM_000828 & Glutamate receptor, ionotrophic, AMPA 3 & 0.023 & 4.328 \\
\hline AFAP1L2 & NM_001001936 & Actin filament associated protein 1-like 2 & 0.014 & 4.202 \\
\hline$T G F B 2$ & NM_001135599 & Transforming growth factor, $\beta 2$ & 0.008 & 4.098 \\
\hline DPYSL5 & NM_020134 & Dihydropyrimidinase-like 5 & 0.007 & 3.537 \\
\hline$M X 1$ & NM_002462 & $\begin{array}{l}\text { Myxovirus (influenza virus) resistance } 1 \text {, } \\
\text { interferon-inducible protein p78 (mouse) }\end{array}$ & 0.036 & 3.304 \\
\hline STMN2 & S82024 & Stathmin-like 2 & 0.023 & 3.237 \\
\hline$C F I$ & NM_000204 & Complement factor I & 0.008 & 3.036 \\
\hline PTPRB & NM_002837 & Protein tyrosine phosphatase, receptor type, B & 0.016 & 2.919 \\
\hline SEMA7A & NM_003612 & $\begin{array}{l}\text { Semaphorin 7A, GPI membrane anchor (John Milton } \\
\text { Hagen blood group) }\end{array}$ & 0.034 & 2.825 \\
\hline SOCS2 & NM_003877 & Suppressor of cytokine signaling 2 & 0.026 & 2.712 \\
\hline$C F I$ & NM_000204 & Complement factor I & 0.042 & 2.603 \\
\hline IRS1 & NM_005544 & Insulin receptor substrate 1 & 0.016 & 2.403 \\
\hline LTBP1 & NM_206943 & Latent transforming growth factor $\beta$ binding protein 1 & 0.041 & 2.393 \\
\hline PRKG1 & NM_006258 & Protein kinase, cGMP-dependent, type I & 0.016 & 2.334 \\
\hline$R T K N 2$ & NM_145307 & Rhotekin 2 & 0.022 & 2.287 \\
\hline$A K A P 12$ & NM_005100 & A kinase (PRKA) anchor protein 12 & 0.023 & 2.280 \\
\hline$R A S G R P 2$ & NM_153819 & $\begin{array}{l}\text { RAS guanyl releasing protein } 2 \text { (calcium and } \\
\text { DAG-regulated) }\end{array}$ & 0.044 & 2.228 \\
\hline GPR124 & NM_032777 & G protein-coupled receptor 124 & 0.041 & 2.202 \\
\hline$I L 17 R D$ & NM_017563 & Interleukin 17 receptor D & 0.016 & 2.162 \\
\hline$R T K N 2$ & $\mathrm{BC} 025765$ & Rhotekin 2 & 0.038 & 2.158 \\
\hline$Q K I$ & NM_206855 & Quaking homolog, KH domain RNA binding (mouse) & 0.003 & 2.054 \\
\hline$T H B D$ & NM_000361 & Thrombomodulin & 0.022 & 2.013 \\
\hline \multicolumn{5}{|c|}{ Immune response } \\
\hline$P B X 1$ & NM_002585 & Pre-B-cell leukemia homeobox 1 & 0.013 & 3.229 \\
\hline$N C F 2$ & NM_000433 & Neutrophil cytosolic factor 2 & 0.044 & 3.151 \\
\hline$T L R 4$ & NM_138554 & Toll-like receptor 4 & 0.038 & 2.518 \\
\hline ANXA3 & NM_005139 & Annexin A3 & 0.024 & 2.217 \\
\hline$B 2 M$ & NM_004048 & $\beta$-2-microglobulin & 0.022 & 2.217 \\
\hline$J A G 2$ & NM_002226 & Jagged 2 & 0.016 & 2.049 \\
\hline \multicolumn{5}{|l|}{ Metabolism } \\
\hline$A L D H 1 A 2$ & NM_170697 & Aldehyde dehydrogenase 1 family, member A2 & 0.005 & 6.147 \\
\hline$C Y P 24 A 1$ & NM_000782 & Cytochrome P450, family 24 , subfamily A, polypeptide 1 & 0.009 & 5.172 \\
\hline$L I P G$ & NM_006033 & Lipase, endothelial & 0.016 & 3.961 \\
\hline$C Y P 24 A 1$ & NM_000782 & Cytochrome P450, family 24 , subfamily A, polypeptide 1 & 0.003 & 3.480 \\
\hline$M G A T 3$ & NM_002409 & $\begin{array}{l}\text { Mannosyl ( } \beta-1,4-) \text {-glycoprotein } \beta-1 \text {, } \\
\text { 4-N-acetylglucosaminyltransferase }\end{array}$ & 0.019 & 3.420 \\
\hline$M E 1$ & L34035 & Malic enzyme 1, NADP(+)-dependent, cytosolic & 0.022 & 3.344 \\
\hline$G D A$ & NM_004293 & Guanine deaminase & 0.022 & 2.956 \\
\hline$M G A T 5 B$ & NM_144677 & $\begin{array}{l}\text { Mannosyl ( } \alpha-1,6-) \text {-glycoprotein } \beta-1 \text {, } \\
6-N \text {-acetyl-glucosaminyltransferase, isozyme B }\end{array}$ & 0.033 & 2.783 \\
\hline ADAM19 & NM_033274 & ADAM metallopeptidase domain 19 (meltrin $\beta$ ) & 0.005 & 2.212 \\
\hline$A L P K 2$ & NM_052947 & $\alpha$-kinase 2 & 0.028 & 2.181 \\
\hline PLTP & NM_006227 & Phospholipid transfer protein & 0.005 & 2.040 \\
\hline
\end{tabular}


Table III. Continued.

Gene symbol Accession number

$\begin{array}{ll}\text { ARG2 } & \text { NM_001172 } \\ \text { CHST8 } & \text { NM_022467 }\end{array}$

Cell cycle, apoptosis

$\begin{array}{ll}\text { SULF1 } & \text { NM_015170 } \\ L C N 2 & \text { NM_005564 } \\ L Y Z & \text { NM_000239 } \\ \text { SGK1 } & \text { NM_005627 } \\ \text { CCND2 } & \text { NM_001759 }\end{array}$

Transcription

$\begin{array}{lc}\text { IRX2 } & \text { NM_033267 } \\ \text { BHLHE22 } & \text { NM_152414 } \\ \text { HOPX } & \text { NM_139211 } \\ \text { NFE4 } & \text { BC036938 } \\ \text { NKX2-1 } & \text { NM_003317 } \\ \text { HIC1 } & \text { NM_006497 } \\ \text { IKZF2 } & \text { NM_001079526 } \\ \text { KLF2 } & \text { NM_016270 } \\ \text { ETS2 } & \text { NM_005239 } \\ \text { BACH2 } & \text { NM_021813 } \\ \text { MEIS1 } & \text { NM_002398 }\end{array}$

Transporter activity

$\begin{array}{ll}S L C 35 F 3 & \text { NM_173508 } \\ M A L 2 & \text { NM_052886 } \\ R B P 1 & \text { NM_002899 } \\ S L C 16 A 2 & \text { NM_006517 } \\ & \\ R H C G & \text { NM_016321 } \\ U C P 2 & \text { NM_003355 }\end{array}$

Others

$\begin{array}{lc}\text { LIMCH1 } & \text { NM_014988 } \\ \text { BICC1 } & \text { AK130049 } \\ \text { SHISA9 } & \text { NM_001145205 } \\ \text { VSIG2 } & \text { NM_014312 } \\ \text { CELF4 } & \text { NM_020180 } \\ \text { ZNF365 } & \text { NM_014951 } \\ \text { SETBP1 } & \text { NM_015559 } \\ \text { C11orf41 } & \text { NM_012194 } \\ \text { ZNF608 } & \text { NM_020747 } \\ \text { SERTAD4 } & \text { NM_019605 } \\ \text { SUSD4 } & \text { NM_017982 } \\ \text { LYPD1 } & \text { NM_144586 } \\ \text { FRMD5 } & \text { NM_032892 } \\ \text { HBA1 } & \text { NM_000558 } \\ \text { HBA2 } & \text { NM_000517 } \\ \text { MAP1LC3A } & \text { NM_032514 } \\ \text { CELF2 } & \text { NM_001025077 } \\ \text { SPANXA1 } & \text { NM_013453 } \\ \text { SPANXD } & \text { NM_032417 } \\ \text { SUSD4 } & \text { NM_001037175 }\end{array}$

Carbohydrate (N-acetylgalactosamine 4-0)
sulfotransferase 8

Gene name

P-value

Fold change

Lipocalin 2

Lysozyme (renal amyloidosis)

Serum/glucocorticoid regulated kinase 1

Cyclin D2

$\begin{array}{ll}0.033 & 2.007 \\ 0.038 & 2.006\end{array}$

Iroquois homeobox 2

Basic helix-loop-helix family, member e22

HOP homeobox

Transcription factor NF-E4

NK2 homeobox 1

Hypermethylated in cancer 1

IKAROS family zinc finger 2 (Helios)

Kruppel-like factor 2 (lung)

V-ets erythroblastosis virus E26 oncogene homolog 2 (avian)

BTB and CNC homology 1, basic leucine zipper transcription factor 2

Meis homeobox 1

$\begin{array}{ll}0.034 & 4.318 \\ 0.013 & 3.799 \\ 0.003 & 2.940 \\ 0.027 & 2.329 \\ 0.005 & 2.088\end{array}$

0.005

0.003

0.003

0.023

0.013

0.003

0.014

0.003

0.005

33.528

6.219

4.453

3.860

3.341

2.818

2.441

2.199

2.183

0.005

2.159

0.033

2.005

Solute carrier family 35, member F3

Mal, T-cell differentiation protein 2

Retinol binding protein 1, cellular

0.003

5.060

0.041

3.569

Solute carrier family 16 , member 2 (monocarboxylic

0.017

2.765

acid transporter 8)

$\mathrm{Rh}$ family, $\mathrm{C}$ glycoprotein

0.005

2.763

Uncoupling protein 2 (mitochondrial, proton carrier)

0.007

2.350

0.003

2.074

LIM and calponin homology domains 1

0.003

23.809

Bicaudal C homolog 1 (Drosophila)

0.013

6.773

Shisa homolog 9 (Xenopus laevis)

V-set and immunoglobulin domain containing 2

0.003

6.281

CUGBP, Elav-like family member 4

4.631

Zinc finger protein 365

0.015

0.008

4.248

SET binding protein 1

Chromosome 11 open reading frame 41

Zinc finger protein 608

SERTA domain containing 4

Sushi domain containing 4

LY6/PLAUR domain containing 1

FERM domain containing 5

0.024

3.504

0.013

3.469

0.003

3.278

0.009

3.272

0.008

3.104

0.034

0.043

3.044

3.033

Hemoglobin, $\alpha 1$

Hemoglobin, $\alpha 2$

Microtubule-associated protein 1 light chain $3 \alpha$

0.013

0.044

0.043

0.035

0.005

CUGBP, Elav-like family member 2

0.023

3.007

3.000

2.993

2.495

2.458

2.445

family member A1

SPANX family, member D

Sushi domain containing 4
0.030

0.022 
Table III. Continued.

\begin{tabular}{|c|c|c|c|c|}
\hline Gene symbol & Accession number & Gene name & P-value & Fold change \\
\hline MAN1A1 & NM_005907 & Mannosidase, alpha, class 1A, member 1 & 0.019 & 2.200 \\
\hline MTUS2 & NM_001033602 & Microtubule associated tumor suppressor candidate 2 & 0.023 & 2.200 \\
\hline$A T A D 3 B$ & AB033099 & ATPase family, AAA domain containing 3B & 0.013 & 2.178 \\
\hline PMEPAl & NM_020182 & Prostate transmembrane protein, androgen induced 1 & 0.003 & 2.163 \\
\hline FILIPIL & NM_182909 & Filamin A interacting protein 1-like & 0.023 & 2.080 \\
\hline FAM20A & NM_017565 & Family with sequence similarity 20, member A & 0.009 & 2.043 \\
\hline$C 1 Q L 1$ & NM_006688 & Complement component $1, \mathrm{q}$ subcomponent-like 1 & 0.045 & 2.027 \\
\hline \multicolumn{5}{|l|}{ Unknown } \\
\hline $\mathrm{N} / \mathrm{A}$ & AK054921 & & 0.013 & 10.114 \\
\hline $\mathrm{N} / \mathrm{A}$ & AB025028 & & 0.041 & 6.451 \\
\hline $\mathrm{N} / \mathrm{A}$ & ВC040881 & & 0.007 & 5.805 \\
\hline $\mathrm{N} / \mathrm{A}$ & AK125437 & & 0.008 & 5.127 \\
\hline $\mathrm{N} / \mathrm{A}$ & CA314451 & & 0.017 & 4.233 \\
\hline $\mathrm{N} / \mathrm{A}$ & AK023954 & & 0.019 & 3.543 \\
\hline$H 19$ & NR_002196 & $\begin{array}{l}\text { H19, imprinted maternally expressed transcript } \\
\text { (non-protein coding) }\end{array}$ & 0.049 & 3.263 \\
\hline Clorf133 & NR_024337 & Chromosome 1 open reading frame 133 & 0.016 & 2.819 \\
\hline$P I K 3 I P 1$ & NM_052880 & Phosphoinositide-3-kinase interacting protein 1 & 0.046 & 2.776 \\
\hline FAM117A & NM_030802 & Family with sequence similarity 117, member A & 0.003 & 2.669 \\
\hline KIAA1199 & NM_018689 & KIAA1199 & 0.013 & 2.643 \\
\hline $\mathrm{N} / \mathrm{A}$ & AI754733 & & 0.010 & 2.606 \\
\hline N/A & BX097190 & & 0.016 & 2.540 \\
\hline C12orf53 & NM_153685 & Chromosome 12 open reading frame 53 & 0.017 & 2.530 \\
\hline $\mathrm{N} / \mathrm{A}$ & AK098514 & & 0.047 & 2.346 \\
\hline $\mathrm{N} / \mathrm{A}$ & ВC041955 & & 0.014 & 2.340 \\
\hline $\mathrm{N} / \mathrm{A}$ & AK024680 & & 0.005 & 2.329 \\
\hline$C C D C 79$ & NM_001136505 & Coiled-coil domain containing 79 & 0.044 & 2.324 \\
\hline $\mathrm{N} / \mathrm{A}$ & $\mathrm{R} 78584$ & & 0.015 & 2.254 \\
\hline$H L A-L$ & NR_027822 & Major histocompatibility complex, class I, L, pseudogene & 0.012 & 2.171 \\
\hline $\mathrm{N} / \mathrm{A}$ & AK025975 & & 0.012 & 2.131 \\
\hline $\mathrm{N} / \mathrm{A}$ & AI161396 & & 0.007 & 2.120 \\
\hline$H C G 26$ & NR_002812 & HLA complex group 26 (non-protein coding) & 0.046 & 2.115 \\
\hline $\mathrm{N} / \mathrm{A}$ & BY798802 & & 0.037 & 2.109 \\
\hline SPOCD1 & NM_144569 & SPOC domain containing 1 & 0.008 & 2.091 \\
\hline $\mathrm{N} / \mathrm{A}$ & AA731781 & & 0.023 & 2.087 \\
\hline PANX2 & NM_052839 & Pannexin 2 & 0.024 & 2.062 \\
\hline $\mathrm{N} / \mathrm{A}$ & AK296148 & & 0.047 & 2.039 \\
\hline
\end{tabular}

P-value, Benjamini-Hochberg false discovery rate of random permutation test; Fold change, ratio of gene expression levels between groups. Gene symbol, accession number, gene name: exported from GeneSpring (from the NCBI databases). FC, fold change; N/A, not available. In each gene ontology functional term, genes were ranked according to fold change (highest to lowest).

Up-and downregulated gene expression profile of organselective metastases. To identify genes that were selectively expressed in each of the three metastatic organs, we performed the fold-change analysis in accordance with the following criteria: genes that were differentially expressed by at least two-fold with $\mathrm{P}<0.05$ in one metastatic organ as compared to metastases in the other two organs. We identified a total of 299 genes, which were potentially involved in multi-organmetastasis features of lung cancer, including the upregulated genes in bone ( 77 genes), lung (106 genes) and liver (56 genes) metastases (Tables II-IV). Moreover, a hierarchical clustering analysis of these 299 upregulated genes using Cluster and TreeView $(14,15)$ obviously separated the three-organ-specific groups of metastatic lesions (Fig. 2A). The genes preferentially expressed in bone metastases were shown as the focused view of the dendrogram (Fig. 2B).

Validation of bone-preferentially expressed genes. To validate the reliability of the expression data obtained by microarray analysis, we performed quantitative RT-PCR for eight genes that were preferentially overexpressed in bone metastasis. The results confirmed the microarray data in all of the tumors tested 
Table IV. Liver metastasis gene expression profile of upregulated genes with $\mathrm{FC}>2.0$, and P-value $<0.05$.

\begin{tabular}{lll}
\hline Gene symbol Accession number $\quad$ Gene name & P-value Fold change \\
\hline
\end{tabular}

Cell adhesion

$\begin{array}{lll}V T N & \text { NM_000638 } & \text { Vitronectin } \\ \text { APOA4 } & \text { NM_000482 } & \text { Apolipoprotein A-IV } \\ \text { KNG1 } & \text { NM_000893 } & \text { Kininogen 1 } \\ \text { DPP4 } & \text { NM_001935 } & \text { Dipeptidyl-peptidase 4 }\end{array}$

0.005

57.713

Extracellular matrix remodeling

$\begin{array}{lll}\text { SOD3 } & \text { NM_003102 } & \text { Superoxide dismutase 3, extracellular } \\ \text { ZG16B } & \text { NM_145252 } & \text { Zymogen granule protein 16 homolog B (rat) }\end{array}$

Superoxide dismutase 3, extracellular

$0.015 \quad 32.078$

$0.005 \quad 11.411$

0.005

2.174

Cell-cell signaling (cytokine/chemokine)

\begin{tabular}{|c|c|c|c|c|}
\hline HGFAC & NM_001528 & HGF activator & 0.009 & 4.183 \\
\hline C4orf7 & NM_152997 & Chromosome 4 open reading frame 7 & 0.027 & 3.725 \\
\hline STC1 & NM_003155 & Stanniocalcin 1 & 0.013 & 2.958 \\
\hline$D A C T 1$ & NM_016651 & $\begin{array}{l}\text { Dapper, antagonist of } \beta \text {-catenin, homolog } 1 \\
\text { (Xenopus laevis) }\end{array}$ & 0.045 & 2.592 \\
\hline STC2 & NM_003714 & Stanniocalcin 2 & 0.048 & 2.222 \\
\hline
\end{tabular}

Signal transduction

$\begin{array}{lc}\text { APOA1 } & \text { NM_000039 } \\ \text { DHCR24 } & \text { NM_014762 } \\ \text { PITPNC1 } & \text { AK094724 } \\ \text { PITPNC1 } & \text { NM_181671 } \\ \text { SORL1 } & \text { NM_003105 } \\ & \\ \text { CALCR } & \text { NM_001742 } \\ \text { ANGPTL4 } & \text { NM_139314 }\end{array}$

Apolipoprotein A-I

0.005

63.590

24-Dehydrocholesterol reductase

0.005

3.597

Phosphatidylinositol transfer protein, cytoplasmic 1

0.034

3.319

Phosphatidylinositol transfer protein, cytoplasmic 1

2.551

Sortilin-related receptor, L(DLR class) A

2.455

repeats-containing

Calcitonin receptor

2.385

Angiopoietin-like 4

2.075

Immune response

NDRG1 NM_006096

$\mathrm{N}$-myc downstream regulated 1

2.073

Cell cycle, apoptosis

$\begin{array}{lc}\text { KLK10 } & \text { NM_002776 } \\ \text { GAS2 } & \text { NM_005256 } \\ \text { Transcription } & \\ \text { ONECUT2 } & \text { NM_004852 } \\ \text { MLXIPL } & \text { NM_032951 } \\ \text { HIF3A } & \text { NM_022462 } \\ \text { TMEM229A } & \text { NM_001136002 } \\ \text { PPARGC1A } & \text { NM_013261 }\end{array}$

Kallikrein-related peptidase 10

0.005

18.807

Growth arrest-specific 2

6.565

One cut homeobox 2

MLX interacting protein-like

Hypoxia inducible factor $3, \alpha$ subunit

Transmembrane protein 229A

0.005

0.014

6.565

$0.025 \quad 4.084$

$0.050 \quad 2.436$

$0.014 \quad 2.356$

$0.047 \quad 2.220$

$\begin{array}{lll}\text { Peroxisome proliferator-activated receptor } \gamma, & 0.027 & 2.039\end{array}$

$\begin{array}{ll}\text { Metabolism } & \\ \text { CPS1 } & \text { NM_001875 } \\ \text { ALDH1L1 } & \text { NM_012190 } \\ \text { HMGCS2 } & \text { NM_005518 } \\ & \\ \text { TMPRSS6 } & \text { NM_153609 } \\ \text { TAT } & \text { NM_000353 } \\ \text { CYP2D6 } & \text { NM_000106 } \\ \text { ACOT12 } & \text { NM_130767 } \\ \text { ADH1C } & \text { NM_000669 } \\ \text { B3GALT1 } & \text { NM_020981 } \\ & \\ \text { PKIB } & \text { NM_181795 } \\ \text { PI3 } & \text { NM_002638 } \\ \text { KHK } & \text { NM_000221 } \\ \text { B3GNT7 } & \text { NM_145236 }\end{array}$

$\begin{array}{lr}0.023 & 13.868 \\ 0.007 & 11.772 \\ 0.005 & 8.819 \\ & \\ 0.031 & 7.609 \\ 0.023 & 6.929 \\ 0.005 & 4.932 \\ 0.029 & 4.353 \\ 0.007 & 4.216 \\ 0.031 & 3.909 \\ & \\ 0.007 & 3.462 \\ 0.044 & 2.873 \\ 0.009 & 2.555 \\ 0.014 & 2.466\end{array}$

$\begin{array}{lll}\text { Carbamoyl-phosphate synthetase 1, mitochondrial } & 0.023 & 13.868\end{array}$

$\begin{array}{lll}\text { Aldehyde dehydrogenase } 1 \text { family, member L1 } & 0.007 & 11.772\end{array}$

$\begin{array}{llr}\text { 3-Hydroxy-3-methylglutaryl-Coenzyme A } & 0.005 & 8.819\end{array}$

synthase 2 (mitochondrial)

$\begin{array}{lll}\text { Transmembrane protease, serine } 6 & 0.031 & 7.609\end{array}$

$\begin{array}{lll}\text { Tyrosine aminotransferase } & 0.023 & 6.929\end{array}$

Cytochrome P450, family 2, subfamily D, polypeptide 6 $0.005 \quad 4.932$

Acyl-CoA thioesterase $12 \quad 0.029 \quad 4.353$

Alcohol dehydrogenase 1C (class I), $\gamma$ polypeptide $\quad 0.007 \quad 4.216$

UDP-Gal:betaGlcNAc $\beta 1,3$-galactosyltransferase, $\quad 0.031 \quad 3.909$

polypeptide 1

$\begin{array}{lll}\text { Protein kinase (cAMP-dependent, catalytic) inhibitor } \beta & 0.007 & 3.462\end{array}$

$\begin{array}{lll}\text { Peptidase inhibitor 3, skin-derived } & 0.044 & 2.873\end{array}$

$\begin{array}{lll}\text { Ketohexokinase (fructokinase) } & 0.009 & 2.555\end{array}$

UDP-GlcNAc: $\beta$ Gal $\beta$-1, $\quad 0.014 \quad 2.466$

3-N-acetylglucosaminyltransferase 7 
Table IV. Continued.

\begin{tabular}{lclcr}
\hline Gene symbol & Accession number & \multicolumn{1}{c}{ Gene name } & \multicolumn{1}{c}{ P-value } & Fold change \\
\hline NAGS & NM_153006 & N-acetylglutamate synthase & 0.029 & 2.341 \\
ENO2 & NM_001975 & Enolase 2 $(\gamma$, neuronal) & 0.007 & 2.171 \\
C10orf10 & NM_007021 & Chromosome 10 open reading frame 10 & 0.031 & 2.074 \\
HK2 & NM_000189 & Hexokinase 2 & 0.033 & 2.050 \\
Transporter activity & & & & \\
HPX & NM_000613 & Hemopexin & 0.005 & 163.982 \\
FABP1 & NM_001443 & Fatty acid binding protein 1, liver & 0.005 & 116.798 \\
SLC38A4 & NM_018018 & Solute carrier family 38, member 4 & 0.009 & 6.334 \\
SLCO4A1 & NM_016354 & Solute carrier organic anion transporter family, & 0.009 & 3.035 \\
& & member 4A1 & 0.038 & 2.474 \\
PAEP & NM_002571 & Progestagen-associated endometrial protein & & \\
The others & & & 0.019 & 2.439 \\
NRN1 & NM_016588 & Neuritin 1 & 0.026 & 2.124 \\
FAM162B & NM_001085480 & Family with sequence similarity 162, member B & 0.036 & 2.068 \\
CLEC2B & NM_005127 & C-type lectin domain family 2, member B & & \\
Unknown & & & 0.049 & 2.023 \\
ANKFN1 & NM_153228 & Ankyrin-repeat and fibronectin type III domain & & \\
N/A & AK129542 & containing 1 & 0.007 & 3.388 \\
N/A & AW444553 & & 0.039 & 2.960 \\
LOC100288985 & XM_002342826 & Hypothetical protein LOC100288985 & 0.050 & 2.753 \\
N/A & BF213738 & & 0.039 & 2.023
\end{tabular}

P-value, Benjamini-Hochberg false discovery rate of random permutation test; Fold change, ratio of gene expression levels between groups. Gene symbol, accession number, gene name: exported from GeneSpring (from the NCBI databases). FC, fold change; N/A, not available. In each gene ontology functional term, genes were ranked according to fold change (highest to lowest).

(Fig. 3). Genes that were previously reported to be involved in bone metastasis or lung-carcinogenesis were identified in our results, including FGFR3, TTYH1, LEFTY1, TM4SF4, CRYM, FOLR1, METTL4 and GUCY1B3. The FGFR3 and TTYHI genes are already reported to be associated with bone metastasis in breast cancers (16). TM4SF4 and CRYM genes were reported as tumor markers in lung cancer (17-19). FOLRl gene was reported to be overexpressed in lung adenocarcinoma $(20,21)$ and has critical involvement in drug resistance (22). METTL4 gene is known to be related to invasiveness and survival in lung cancer (23), and GUCY1B3 gene was reported to be involved in osteoclast signaling pathway (24). These findings suggest that those genes may potentially contribute to the bone-preferential metastasis of NSCLC cells.

\section{Discussion}

The molecular basis of organ tropism, one of the main characteristics of cancer metastasis, is still largely obscure. It has been documented that different types of cancer produce metastases at preferred secondary sites, depending on organ-susceptibility to specific cells. Stephen Paget proposed the 'seed and soil' theory that the molecular interactions between metastatic cells (seeds) and stromal microenvironment (soil) play critical roles throughout the multi-process of metastasis $(25,26)$. In this study, we used a previously established multi-organ metastasis mouse model (13), in which cancer cells were inoculated directly into the tail vein that travels to the lungs. Although the tumor cells can be trapped at the lungs as first capillary beds, there were also possibilities that the cells circulate systemically and can reach any organ. Therefore, the analysis of transcriptomic profiles of metastatic lesions in the three organs, bone, lung and liver, can lead to the identification of genetic changes in later steps of the metastasis cascade, when tumor cells have already homed to the specific organ. These changes also reflect the interaction between cancer cells and the local or host cells in the 'microenvironment' of the organ. To form metastatic tumors in a certain organ, cancer cells when homing to this specific organ must interact with the host microenvironment (25-27). To do so, certain molecular programs in cancer cells are activated $(25,27)$. Hence, to elucidate the specific changes of cancer cells in different metastatic organs, we performed microdissection to collect a pure population of cancer cells in metastatic lesions in each type of organ (three organs of five mice, totally 15 lesions), subsequently coupled with DNA microarray analysis. Hierarchical clustering analysis of the 299 organ preferentially expressed genes revealed that they seemed to reflect the organ selectivity of metastatic cells (Fig. 2). In particular, we here focused on genes that were preferentially expressed in bonemetastases.

Among them, we demonstrated that the expression levels of FGFR3 and TTYH1 genes were significantly upregulated 
A

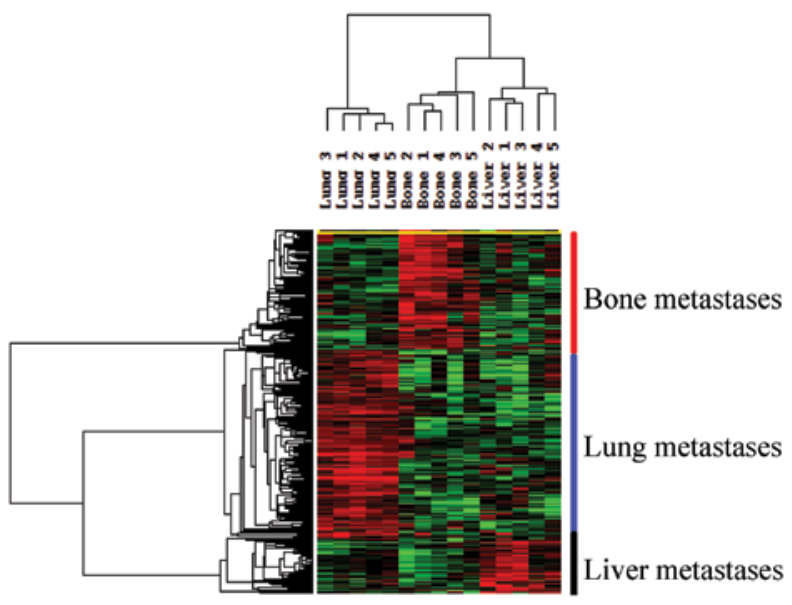

B
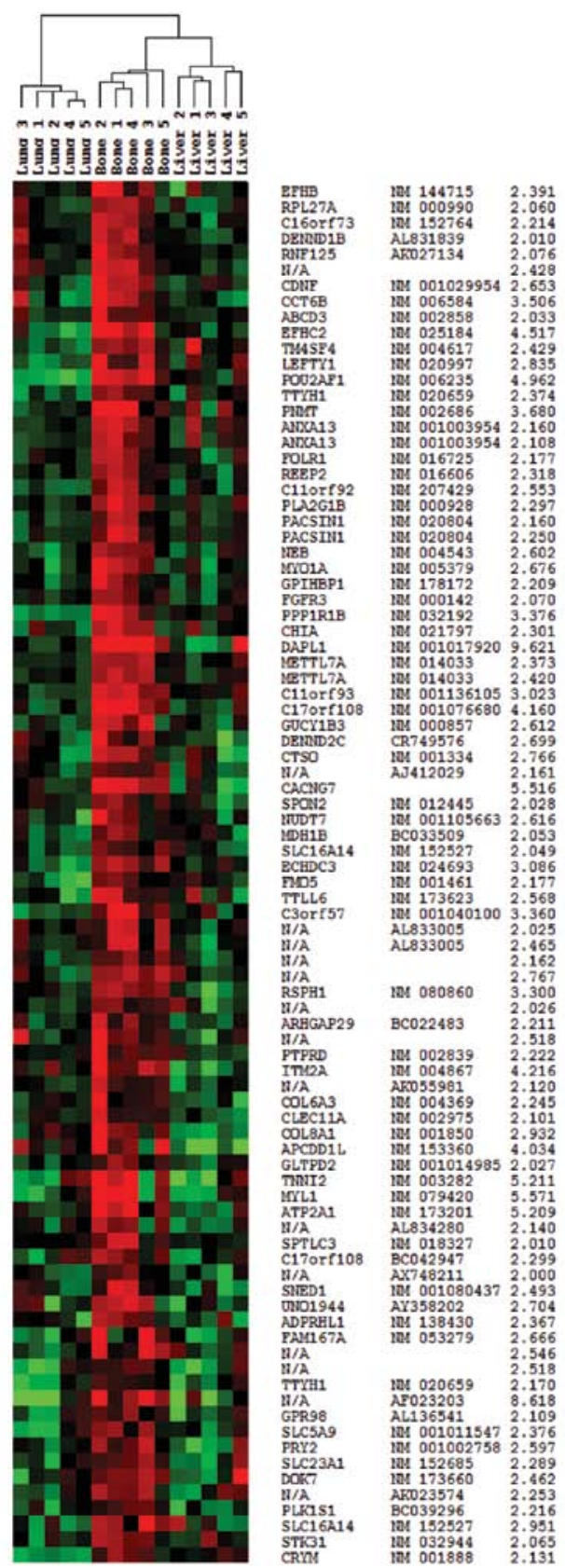

RF-hand dowain family;
ribosomal protein $\mathrm{L} 27 \mathrm{a}$

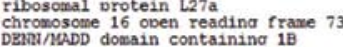
DEMI/NADD domain contain
rina finaer protein 125

cerebral doodmine neurotroohic factor chaperonin containina TCP1, subunit $6 \mathrm{~B}$ (zeta 2) ATP-bindina cassette. sub-faxily D (ALD). wexber 3 BF-hand domain (C-terminal) containina transmembrane $4 \mathrm{~L} s 1 \mathrm{x}$ familv member
left-rioht deternination factor 1 pou class 2 associating factor 1 tweety homoloo 1 (Drosoobilia)

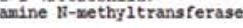
annexin $\mathrm{A13}$ folate receotor 1 (adult) chroxosome 11 open reading frame 92 rotein kinase $\mathrm{C}$ and casein $\mathrm{x}$ inseass protein kinase $c$ and casein $k$ inase substrate in ne wrosin IA alvcosylphosphatidrlinositol anchored hiah density chitinase. acidic death associated protein-1ike
methvitransferase like $7 \AA$ methvitransferase like $7 \lambda$ chromosone 11 oven readina fraxe 93 chrounosome 17 oven readina frame 108
cuanvlate crclase 1 . soluble. beta 3 DERn/1ate crolase 1. Soluble. catheosin o

calcium channel. voltace-devendent. daswa subunit nudix (nucleoside diphosphate linked xolety $x$ ) - tro malate dehrdrocenase 1B. NDD (soluble) (xonocarboxr11 enorl Coenzrme A broratase domain containina 3 tubulin trrosine licase-1ike familv, wenber 6 reading frase 5

radial spoke head 1 homolog (Chlanydoxonas) Rho GTPase activating protein 29 protein trrosine phosohatase. receutor type, D colladen. troe VI. aloha 3 member $A$ collacen. true VIII. alvha ${ }^{1}$ dom-reculated 1-11ke alvcolibid transfer protein domain containina 2 mrosin. lioht chain 1 . alkaili : skeletal. fast
ATPase. Cat+ transporting, cardiac muscie, fast tw serine valmitorltransferase, 1ong chain base subun sushi. nidocen and EGP-1ike dowains 1 ADP-ribosylingdrolase like 1 family with secquence similarity 167 , rember A

treety homolog 1 (Drosophila)

6 orotein-coupled receptor 98
solute carrier familif 5 (sodius/alucose cotranspor PTPII13-11ke. $Y$-1inked 2 (nucleobase transporters) solute carrier famil:
docking protein 7

volo-1ike kinase 1 substrate 1

solute cartier famili 16 . mexber 14 imonocarboxy11 serine/threonine

Figure 2. Hierarchical cluster analysis of 15 metastatic lesions. (A) Dendrogram showing the highly expressed genes in metastases in the bone, lung and liver Total: 299 genes. (B) A section of the above dendrogram showing genes preferentially expressed in bone metastases. In the dendrograms, row represents a single gene; column represents the metastatic lesion; and color: red, green or black indicates high, low or unchanged expression level, respectively, of corresponding gene relative to the mean. 

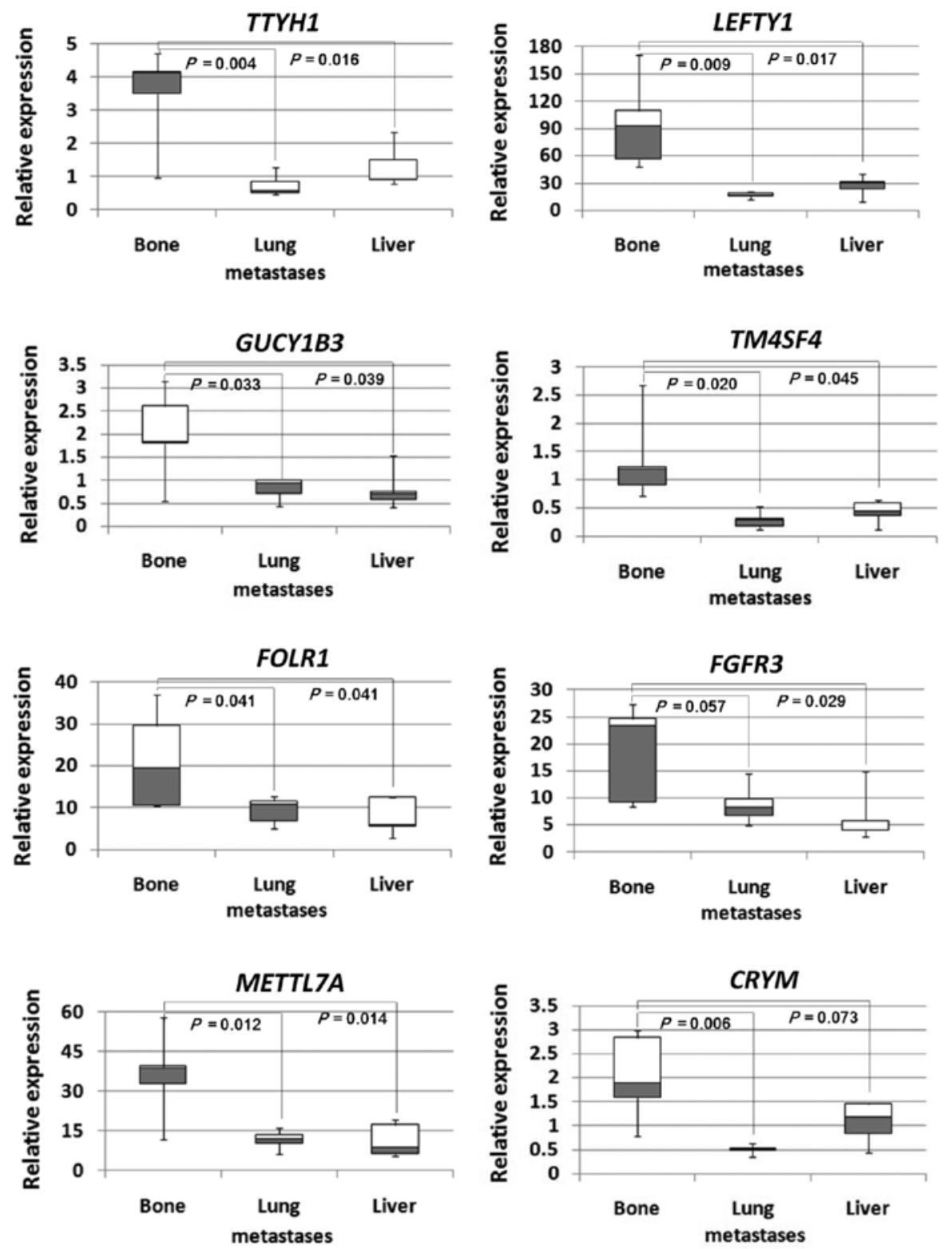

Figure 3. Box plots showing expression levels of eight selected genes in bone, lung and liver metastatic legions. GAPDH was used for normalization. Data are expressed as the fold increase over ACC-LC319/bone2 original cells (set at 1.0), and represent the mean \pm SE of three independent experiments.

in bone metastasis compared with metastasis in lung or liver. These genes have been previously reported to be upregulated in human breast cancer bone metastasis in clinical specimen (16). Smid et al reported analysis of expression profiling in 107 human breast cancer patients who had relapse in bone or other sites in the body, and identified a panel of 69 genes that were upregulated in bone relapse, which included FGFR3 and TTYH1 (16).

FGFR3, encoding a receptor tyrosine kinase for fibroblast growth factor, was reported to be overexpressed in $\sim 15-20 \%$ cases of myeloma, or constituvely activated due to mutations in most of bladder cancers and other solid tumors, including lung cancers. Fibroblast growth factors (FGF) are bone-derived factors abundant in the bone environment $(6,26)$, therefore it is reasonable that lung cancer cells highly expressing FGFR3 might be more selectively colonized in bone than in lung or liver. In addition, the FGF-FGFR3 signaling pathway via Ras-MAPK and PI3K in cancer cells may lead to enhanced cell proliferation and migration (reviewed in refs. 28 and 29). TTYH1, an endoplasmic-localized protein, was reported to be a $\mathrm{Ca}^{2+}$-binding protein playing critical roles in mitosis and cell proliferation (30). This molecule may therefore be essential for the cancer cells homing to the bone, and may contribute to the growth advantage of the metastatic tumors in the bone. LEFTY1 (also known as LEFTY-B), another promising target gene in the bone metastases profile, was confirmed to be significantly upregulated in bone metastasis. LEFTY1 was reported to be a secreted molecule of the TGF- $\beta$ superfamily involved in the Nodal signaling pathway, and a marker of the stemness of cells (31-33), and to contribute to the remodeling process of the extracellular matrix (34). In contrast, LEFTY1 also plays an important role as an inhibitor of Nodal, a crucial component involved in metastatic melanoma cells, in a negative feedback mechanism (reviewed in ref. 33).

Recently, it was reported that cancer stem cells possess tumorigenic, invasive and migratory characteristics $(25,27)$, and 
tumor cell plasticity (33). These individual lines of evidence suggest that LEFTY1 may be involved in metastasis. Moreover, GUCY1B3, encoding an enzyme that catalyzes the conversion of GTP to cyclic GMP, is well-known to be involved in the pathway of nitride oxide signaling, which is one of the major post differentiation pathways in the osteoclast (24). It is reported that the enhancement of a soluble form of GUCY1B3 led to the activation of the osteoclasts in the osteolytic bone metastasis process. Moreover, this protein enhances tumor growth of glioma (35) and angiogenesis in both glioma and chorioallantoic membrane $(35,36)$, and plays paradoxical roles in the proliferation of cancer cells (37), suggesting that GUCY1B3 could be involved in bone metastasis.

Furthermore, among the genes highly expressed in lung metastasis, we identified genes encoding surfactant protein $\mathrm{C}$ and D (SFTPC and SFTPD: 192- and 95-fold changes, respectively). Serum levels of SFTPC and SFTPD were previously reported to be elevated in mice with lung tumors $(38,39)$. In humans, a research on lung adenocarcinoma showed the upregulation of $S F T P C$ and $S F T P D$, especially $S F T P D$, in lymph node metastatic lesions (17 in 23 cases of metastases or micrometastases) (40). Although specific role(s) of these molecules in lung metastasis are not characterized so far, our findings raise the possibilities that SFTPC and SFTPD proteins regulate the process of metastasis in general, or specifically, lung colonization, of the cancer cells in this multi-organ metastasis mouse model. Moreover, Claudin-18 (CLDN18), a tight junction molecule, was upregulated $\sim 21$-fold in lung metastases as compared with metastases in other organs. A recent immunotherapeutic strategy using auto-antibody against CLDN18 shows that the formation of pulmonary metastasis was significantly reduced in mice inoculated intravenously with colon cancer cells (41), suggesting that CLDN18 could be a specific molecule for controlling metastasis, especially lung metastases. In addition, Dickkopf-1 (DKK1), a secreted protein that negatively regulates the Wnt signaling pathway, was upregulated 11-fold in lung metastases. It has been reported that DKK1 is a serologic and prognostic biomarker for lung cancers $(42,43)$.

Finally, we focused on genes that were rank-ordered among genes that were preferentially expressed in liver metastasis, namely hemopexin (HPX) and vitronectin (VTN). HPX and VTN proteins belong to the hemopexin superfamily which includes matrix metalloproteinases (MMPs). HPX which is highly expressed in the liver binds to hemes and negates the toxic effect of hemes. It is remarkable that there are hundreds of proteins, including MMPs, containing one or several motifs that structurally and functionally resemble parts of the HPX protein (review in ref. 44). A latest report shows that small-molecule compounds that selectively target the hemopexin domain of MMP-9 can control tumor growth and inhibit lung metastasis in breast cancer xenograft model in mice (45). Moreover, VTN, an extracellular protein that interacts with many integrins, is also expressed highly in the liver, and was previously reported to be upregulated in primary hepatocellular carcinoma (46), or liver metastases from colorectal cancer $(46,47)$ and neuroblastoma (48).

Thus, we identified a dozen potential metastasis-related molecules including other unknown functional molecules. However, relating to bone metastasis, there were no overlapping genes compared with previous report in SCLC (using SBC-5 cell line) (13). This may reflect the fact that there are distinctive biologic processes involved in SCLC or NSCLC bone metastasis, although in both cases bone metastatic lesions were of same osteolytic phenotype. Vicent $e t$ al reported a lung cancer bone metastasis gene profile using NSCLC (NCI-H460, a large cell carcinoma cell line), by comparing the transcriptomes of the sublines possessing highly bone metastatic ability and the parental cell lines (12). However, none of the genes in their data were identified in our bone metastasis gene profile. This discrepancy on microarray data may be due to several factors. In this study, we focused on lung cancer bone metastases from NSCLC (adenocarcinoma, $60-70 \%$ of non-resectable NSCLC), not SCLC (4). In fact, SCLC consists of only 15-20\% of lung cancers, whereas NSCLC consists of $80-85 \%$, and the natural course as well as the molecular basis of SCLC is quite distinct from NSCLC $(2,4)$. The above evidence suggests that there were differences in the biology of bone metastases in NSCLC in comparison with SCLC.

In conclusion, through a human NSCLC cell line with enhanced bone metastasis ability in a multi-organ metastasis mouse model coupled with microarray analysis, we identified dozens of genes which were potentially involved in metastases to the bone, lung, and liver. However, it will be necessary to perform further functional analyses using gain- or loss-offunction approaches in mouse models and validation in human clinical samples. Our findings should be helpful for better understanding of molecular aspects of the metastatic process in different microenvironments, especially in bone metastases, and could lead to molecular target-based anticancer drugs and prevention of metastasis.

\section{Acknowledgements}

We thank Drs Tomoya Fukawa, Masato Komatsu and Kazuma Kiyotani of Division of Genome Medicine, Institute for Genome Research, The University of Tokushima for helpful discussion, and Dr Hirohisa Ogawa of Department of Molecular and Environmental Pathology, Institute of Health Biosciences, the University of Tokushima Graduate School for studious guidance in examination on pathology.

\section{References}

1. Jemal A, Bray F, Center MM, et al: Global cancer statistics. CA Cancer J Clin 61: 69-90, 2011 (Erratum in CA Cancer J Clin 61: 134, 2011).

2. Herbst RS, Heymach JV and Lippman SM: Lung cancer. N Engl J Med 359: 1367-1380, 2008.

3. Al Husaini H, Wheatley-Price P, Clemons M, et al: Prevention and management of bone metastases in lung cancer: a review. J Thorac Oncol 4: 251-259, 2009.

4. Stenbygaard LE, Sørensen JB, Larsen H, et al: Metastatic pattern in non-resectable non-small cell lung cancer. Acta Oncol 38: 993-998, 1999.

5. Sone S and Yano S: Molecular pathogenesis and its therapeutic modalities of lung cancer metastasis to bone. Cancer Metastasis Rev 26: 685-689, 2007.

6. Roodman GD: Mechanisms of bone metastasis. N Engl J Med 350: 1655-1664, 2004.

7. Mundy GR: Metastasis to bone: causes, consequences and therapeutic opportunities. Nat Rev Cancer 2: 584-593, 2002.

8. Ibrahim T, Flamini E, Mercatali L, et al: Pathogenesis of osteoblastic bone metastases from prostate cancer. Cancer 116: 1406-1418, 2010 (Erratum in: Cancer 116: 2503, 2010).

9. Weilbaecher KN, Guise TA and McCauley LK: Cancer to bone: a fatal attraction. Nat Rev Cancer 11: 411-425, 2011. 
10. Rose AA and Siegel PM: Emerging therapeutic targets in breast cancer bone metastasis. Future Oncol 6: 55-74, 2010.

11. Kakiuchi S, Daigo Y, Tsunoda T, et al: Genome-wide analysis of organ-preferential metastasis of human small cell lung cancer in mice. Mol Cancer Res 1: 485-499, 2003.

12. Vicent S, Luis-Ravelo D, Antón I, et al: A novel lung cancer signature mediates metastatic bone colonization by a dual mechanism. Cancer Res 68: 2275-2285, 2008.

13. Otsuka S, Hanibuchi M, Ikuta K, et al: A bone metastasis model with osteolytic and osteoblastic properties of human lung cancer ACC-LC-319/bone2 in natural killer cell-depleted severe combined immunodeficient mice. Oncol Res 17: 581-591, 2009.

14. Eisen MB, Spellman PT, Brown PO, et al: Cluster analysis and display of genome-wide expression patterns. Proc Natl Acad Sci USA 95: 14863-14868, 1998 .

15. de Hoon MJL, Imoto S, Nolan J, et al: Open source clustering software. Bioinformatics 20: 1453-1454, 2004.

16. Smid M, Wang Y, Klijn JG, et al: Genes associated with breast cancer metastatic to bone. J Clin Oncol 24: 2261-2267, 2006.

17. Wang KK, Liu N, Radulovich N, et al: Novel candidate tumor marker genes for lung adenocarcinoma. Oncogene 21: 7598-7604, 2002.

18. Chong IW, Chang MY, Chang HC, et al: Great potential of a panel of multiple hMTH1, SPD, ITGA11 and COL11A1 markers for diagnosis of patients with non-small cell lung cancer. Oncol Rep 16: 981-988, 2006.

19. Nakamura N, Kobayashi K, Nakamoto M, et al: Identification of tumor markers and differentiation markers for molecular diagnosis of lung adenocarcinoma. Oncogene 25: 4245-4255, 2006.

20. Iwakiri S, Sonobe M, Nagai S, et al: Expression status of folate receptor alpha is significantly correlated with prognosis in nonsmall-cell lung cancers. Ann Surg Oncol 15: 889-899, 2008.

21. Jin M, Kawakami K, Fukui Y, et al: Different histological types of non-small cell lung cancer have distinct folate and DNA methylation levels. Cancer Sci 100: 2325-2330, 2009.

22. Sánchez-del-Campo L, Montenegro MF, Cabezas-Herrera J, et al: The critical role of alpha-folate receptor in the resistance of melanoma to methotrexate. Pigment Cell Melanoma Res 22: 588-600, 2009

23. Liu R, Wang X, Chen GY, et al: The prognostic role of a gene signature from tumorigenic breast-cancer cells. N Engl J Med 356: 217-226, 2007.

24. Blair HC, Robinson LJ and Zaidi M: Osteoclast signaling pathways. Biochem Biophys Res Commun 328: 728-738, 2005.

25. Talmadge JE and Fidler IJ: AACR centennial series: the biology of cancer metastasis: historical perspective. Cancer Res 70 $5649-5669,2010$

26. Casimiro S, Guise TA and Chirgwin J: The critical role of the bone microenvironment in cancer metastases. Mol Cell Endocrinol 310: 71-81, 2009.

27. Hanahan D and Weinberg RA: Hallmarks of cancer: the next generation. Cell 144: 646-674, 2011.

28. Haugsten EM, Wiedlocha A, Olsnes S, et al: Roles of fibroblast growth factor receptors in carcinogenesis. Mol Cancer Res 8 : 1439-1452, 2010.

29. L'Hôte CG and Knowles MA: Cell responses to FGFR3 signalling: growth, differentiation and apoptosis. Exp Cell Res 304: 417-431, 2005

30. Kumada T, Yamanaka Y, Kitano A, et al: Ttyh1, a Ca ${ }^{2+}$-binding protein localized to the endoplasmic reticulum, is required for early embryonic development. Dev Dyn 239: 2233-4225, 2010.
31. Besser D: Expression of Nodal, Lefty-A, and Lefty-B in undifferentiated human embryonic stem cells requires activation of Smad2/3. J Biol Chem 279: 45076-45084, 2004.

32. Dvash T, Sharon N, Yanuka O, et al: Molecular analysis of LEFTY-expressing cells in early human embryoid bodies. Stem Cells 25: 465-472, 2007.

33. Hendrix MJ, Seftor EA, Seftor RE, et al: Reprogramming metastatic tumour cells with embryonic microenvironments. Nat Rev Cancer 7: 246-255, 2007.

34. Mason JM, Xu HP, Rao SK, et al: Lefty contributes to the remodeling of extracellular matrix by inhibition of connective tissue growth factor and collagen mRNA expression and increased proteolytic activity in a fibrosarcoma model. J Biol Chem 277: 407-415, 2002.

35. Saino M, Maruyama T, Sekiya T, et al: Inhibition of angiogenesis in human glioma cell lines by antisense RNA from the soluble guanylate cyclase genes, GUCY1A3 and GUCY1B3. Oncol Rep 12: 47-52, 2004

36. Pyriochou A, Beis D, Koika V, et al: Soluble guanylyl cyclase activation promotes angiogenesis. Pharmacol Exp Ther 319: 663-671, 2006

37. Mujoo K, Sharin VG, Martin E, et al: Role of soluble guanylyl cyclase-cyclic GMP signaling in tumor cell proliferation. Nitric Oxide 22: 43-50, 2010

38. Mason RJ, Kalina M, Nielsen LD, et al: Surfactant protein C expression in urethane-induced murine pulmonary tumors. Am J Pathol 156: 175-182, 2000.

39. Zhang F, Pao W, Umphress S, et al: Serum levels of surfactant protein D are increased in mice with lung tumors. Chest 125 (Suppl 5): 109, 2004.

40. Betz C, Papadopoulos T, Buchwald J, et al: Surfactant protein gene expression in metastatic and micrometastatic pulmonary adenocarcinomas and other non-small cell lung carcinomas: detection by reverse transcriptase-polymerase chain reaction. Cancer Res 55: 4283-4286, 1995.

41. Klamp T, Schumacher J, Huber G, et al: Highly specific autoantibodies against claudin-18 isoform 2 induced by a chimeric $\mathrm{HBcAg}$ virus-like particle vaccine kill tumor cells and inhibit the growth of lung metastases. Cancer Res 71: 516-527, 2011.

42. Yamabuki T, Takano A, Hayama S, et al: Dikkopf-1 as a novel serologic and prognostic biomarker for lung and esophageal carcinomas. Cancer Res 67: 2517-2525, 2007.

43. Sheng SL, Huang G, Yu B, et al: Clinical significance and prognostic value of serum Dickkopf-1 concentrations in patients with lung cancer. Clin Chem 55: 1656-1664, 2009.

44. Piccard H, Van den Steen PE and Opdenakker G: Hemopexin domains as multifunctional liganding modules in matrix metalloproteinases and other proteins. J Leukoc Biol 81: 870-892, 2007.

45. Dufour A, Sampson NS, Li J, et al: Small-molecule anticancer compounds selectively target the hemopexin domain of matrix metalloproteinase-9. Cancer Res 71: 4977-4988, 2011.

46. Edwards S, Lalor PF, Tuncer C, et al: Vitronectin in human hepatic tumours contributes to the recruitment of lymphocytes in av $\beta 3$-independent manner. Br J Cancer 95: 1545-1554, 2006.

47. Yoshioka T, Nishikawa Y, Ito R, et al: Significance of integrin $\alpha v \beta 5$ and erbB3 in enhanced cell migration and liver metastasis of colon carcinomas stimulated by hepatocyte-derived heregulin. Cancer Sci 101: 2011-2018, 2010.

48. Kuwashima N: Organ-specific adhesion of neuroblastoma cells in vitro: correlation with their hepatic metastasis potential. J Pediatr Surg 32: 546-551, 1997. 